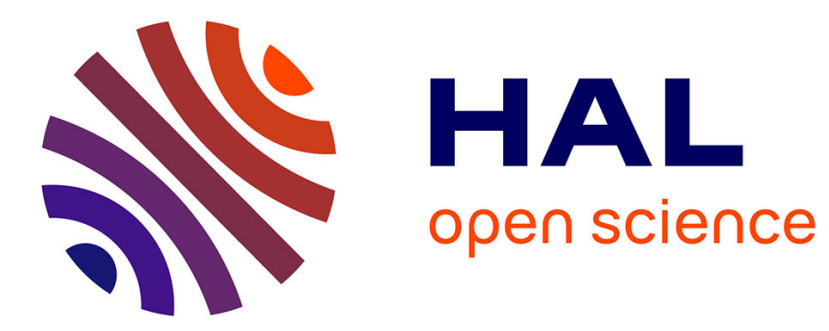

\title{
Retirement intentions of older migrant workers: Does health matter?
}

\author{
Nicolas Gérard Vaillant, François-Charles Wolff
}

\section{To cite this version:}

Nicolas Gérard Vaillant, François-Charles Wolff. Retirement intentions of older migrant workers: Does health matter?. 2012. hal-00671527

\section{HAL Id: hal-00671527 \\ https://hal.science/hal-00671527}

Preprint submitted on 17 Feb 2012

HAL is a multi-disciplinary open access archive for the deposit and dissemination of scientific research documents, whether they are published or not. The documents may come from teaching and research institutions in France or abroad, or from public or private research centers.
L'archive ouverte pluridisciplinaire HAL, est destinée au dépôt et à la diffusion de documents scientifiques de niveau recherche, publiés ou non, émanant des établissements d'enseignement et de recherche français ou étrangers, des laboratoires publics ou privés. 


\title{
EA 4272
}

\section{Retirement intentions of older migrant workers: Does health matter?}

\author{
Nicolas Gérard Vaillant * \\ François-Charles Wolf **
}

\begin{abstract}
$2012 / 02$
*LEM, Université Catholique de Lille (FLSEG) et Institut des Stratégies et Techniques de Communication

**LEMNA - Université de Nantes et INED - Paris
\end{abstract}

Laboratoire d'Economie et de Management Nantes-Atlantique Université de Nantes

Chemin de la Censive du Tertre - BP 52231

44322 Nantes cedex 3 - France

www.univ-nantes.fr/iemn-iae/recherche

UNIVERSITÉ DE NANTES 


\title{
Retirement intentions of older migrant workers: Does health matter?
}

\author{
Nicolas Gérard Vaillant ${ }^{*}$ \\ François-Charles Wolff ${ }^{* *}$
}

January 2012

\begin{abstract}
This paper investigates the effect of self-assessed health on retirement plans of older migrants. As immigration is primarily associated with labor considerations, the role of economic incentives in the migration decision suggests that health could play a minor effect in immigrants' decision to retire. Using detailed data on immigrants living in France collected in 2003, we examine the role of health on early retirement intentions using simultaneous, recursive models that account for the fact that subjective health is potentially endogenous. Being in poor health increases the intention of migrant workers to retire early, but the subjective health outcomes have little influence on retirement plans.
\end{abstract}

JEL Classification: I19, J26

Keywords: Retirement intention, self-assessed health, immigrants, France

\footnotetext{
* LEM (UMR 8179 CNRS), Université Catholique de Lille (FLSEG, Centre de Recherche sur le Capital Humain) and Institut des Stratégies et Techniques de Communication. E-mail: nicolas.vaillant@icl-lille.fr http://flseg.icl-lille.fr/ http://www.istc.fr http://ngvaillant.e-monsite.com/

${ }^{* *}$ Corresponding author. LEMNA, Université de Nantes, BP52231 Chemin de la Censive du Tertre, 44322 Nantes Cedex; CNAV and INED, Paris, France.

E-mail: francois.wolff@univ-nantes.fr http://www.sc-eco.univ-nantes.fr/ ffwolff/
} 


\section{Introduction}

With the increased ageing of the population, early retirement creates a challenge for public policies in virtually all developed countries and especially in Europe, where labor force participation rates remain very low at older ages (Brugiavini, 2001). Economists have highlighted three main factors that are likely to influence retirement decisions.

First, economic variables and financial incentives are important in the selection of the optimal retirement date (Lazear, 1986). Secondly, poor working and employment conditions increase premature departures from working life as shown in Siegrist et al. (2006). Finally, being in poor health is frequently mentioned as an explanation for early retirement. As discussed in the survey of Lumsdaine and Mitchell (1999, pp. 3282-3283), health is expected to influence retirement decisions through two main explanations that are respectively financial considerations and preferences.

On the one hand, health will strongly influence employee compensation opportunities. Individuals in poor health are more likely to be absent and less productive, which reduces their current wages, and they may also invest less in job-specific skills. In the long run, this may affect their employability. Older workers, who experience health problems more often, may choose to retire earlier because of these less attractive job opportunities. Retirement decisions are then expected to depend on the relative magnitude of a substitution effect and an income effect. Although working becomes less valuable because of lower pay, there may still be incentives for people in poor health to work as they will preserve their health care benefits in that case ${ }^{1}$.

On the other hand, health may have an effect on the individual perception of the utility derived from consumption and leisure ${ }^{2}$. The job of a worker who is in poor health is expected to become more demanding because of reduced physical capacity, which should increase the disutility of work. A worker having physical problems will certainly be more interested in spending time at home than in undertaking painful activities. At the same time, the situation may be very different for older highincome and low-income workers. It is likely that poor health makes leisure more appealing for affluent white-collar workers. Also, severely ill individuals may have a very different perception of time lines, with a greater emphasis on leisure time.

Health is thus expected to play an important role in the decision to retire. An interesting question is whether health problems influence retirement intentions more strongly than economic factors do. Unfortunately, it is somewhat difficult to identify the role of health variables on retirement plans when considering individual data. This mainly occurs because of the use of subjective self-reported

\footnotetext{
${ }^{1}$ Another mechanism is the possibility for individuals in poor health to work less in the medium term to receive either public or private benefits related to disability for a longer period of time.

${ }^{2}$ Note here that the decision to retire of a given individual is also likely to affect the labor supply (and hence retirement) choices of the other family members. For instance, a younger wife may choose to retire earlier in order to care for her husband in poor health. On caregiving and labor supply decisions, see Heitmueller (2007).
} 
measures of health, which sets up an endogeneity problem. According to the so-called "justification hypothesis" discussed in Bazzoli (1985), Bound (1991) and Dwyer and Mitchell (1999) among others, the estimated health effect given by the self-assessed outcome is likely to be biased if individuals consider their health status as a justification for retiring early.

In this setting, people who are dissatisfied with their labor activities will tend to exacerbate their current health problems and consequently leave the labor force early: "When subjective health assessments measure leisure preferences instead of "true health capacity", estimates of health effects will tend to be biased in the direction of poorer reported health driving retirement" (Dwyer and Mitchell, 1999, p. 174). Keeping in mind the potential relevance of the justification hypothesis is important when assessing the relative contribution of health and economic variables. If people who prefer early retirement claim being in poor health more often, then the self-reported health effect in econometric models will be overstated. One thus expects the role of economic factors to increase once accounting for endogeneity and measurement errors ${ }^{3}$.

In this paper, we investigate the effect of health on retirement intentions using data on older migrant workers living in France. Knowing the relative contribution of health variables and economic factors in the context of migration is a challenging issue. Numerous economists have suggested that differences in net economic advantages between the host and receiving countries were the main causes of international migration (Lalonde and Topel, 1997). Migration has primarily been associated with labor considerations during the last decades, but this perception has now to be revised given the ageing of migrants. In almost all industrialized countries, the proportion of migrants having retired or nearing retirement has increased substantially.

From an ex ante point of view, migrants may have incentives to postpone their retirement decision compared to natives for at least two reasons. The first one is an earnings differential between the host country and the country of origin. All migrants having left a poor country of origin know that they will certainly benefit from much better economic conditions by staying in France, especially as the earning gap may increase during old age $\mathrm{A}^{4}$. At the same time, if migrants keep their retirement benefits whatever their location, then they could be rich retirees in their country of origin since developing countries have a low cost of living. The second one is that migrants who arrived in France later in life will receive very small pensions because they have not contributed enough.

\footnotetext{
${ }^{3}$ From an empirical perspective, there is no clear consensus to date on the justification bias. Comparing the self-assessed measurement of health reported by an individual respectively before and after retirement, Bazzoli (1985) finds that the self-reported outcome is poorer in the latter case and that economic variables play a more important role than health in retirement decisions. Conversely, in Dwyer and Mitchell (1999), poor health is associated with earlier retirement plans, but the self-assessed health measures are not endogeneously determined with labor supply decisions. McGarry (2004) also shows that the role of subjective health measures on retirement plans is more important than that of financial variables.

${ }^{4}$ Further, there is no pension scheme in many developing countries and older people have to rely essentially on private transfers from their adult children (and to co-reside with them).
} 
Clearly, the role of economic incentives in the migration decision suggests that health may play a weak role in the decision to retire among migrants. To study the effect of being in poor health on retirement intentions, we have used a data set collected between November 2002 and February 2003 on the immigrant population aged 45 to 70 living in France at that time $e^{5}$. This survey includes detailed questions about the respondents' characteristics, including retirement intentions and two self-rated health variables (self-assessed health and chronic disability).

Specifically, we study the role of health on early retirement intentions using a sample of immigrants aged from 45 to 59 and working at the time of the survey. Drawing on an instrumental variable strategy, we estimate recursive models that account for the fact that the subjective health outcomes are discrete and potentially endogenous in the retirement equation. Our results indicate that in France, being in poor health significantly increases the intention of migrant workers to retire earlier. Furthermore, there is little evidence in support of the justification bias. However, subjective health outcomes have less influence on retirement plan than economic variables.

The remainder of our paper is organized as follows. In Section 2, we present the data and describe the pattern of retirement expectations among immigrants. The estimation strategy is exposed in Section 3 and the different results from our econometric analysis are discussed in Section 4. Lastly, Section 5 concludes.

\section{Description of the data}

To study the influence of health on migrants' retirement plans, we use a cross-sectional survey on immigrants' experience of ageing and retirement conducted in France between November 2002 and February 2003. The focus of the "Passage à la Retraite des Immigrés" survey (PRI hereafter) was on the elderly immigrant population residing in France at the time of survey. Immigration is defined by place of birth (outside France) and nationality of birth (non-French). This includes people who have acquired French citizenship by naturalization, but excludes French citizens by birth, but born in other countries.

With respect to other surveys on immigration usually dealing with integration, the main purpose of the PRI survey was to study the immigrants' transition from work to retirement (Attias-Donfut et al., 2005). The PRI survey contains detailed information on the respondents' demographic and economic characteristics, including social networks, migration history, work and retirement, health, support and intergenerational transfers, household income, savings and standards of living. The questionnaire also deals with plans for retirement. The sample includes 6211 observations, more

\footnotetext{
${ }^{5}$ A comparison between the migrant and native populations is very difficult in this context. There may be some selection problems because of the "healthy immigrant effect": immigrants are usually in relatively better health on arrival in the host country compared to native-born individuals (McDonald and Kennedy, 2004).
} 
than $70 \%$ of the respondents coming from three southern European countries (Italy, Portugal, Spain) and from three North African countries (Algeria, Morocco, Tunisia).

In what follows, we focus on respondents who have not yet retired or who are about to retire. As we are interested in the effect of health on retirement decisions, we further restrict our attention to working migrants, insofar as non-working respondents could be tempted to justify their inactivity by reporting a poor health status (see the discussion in McGarry, 2004). Finally, we only consider immigrants who were less than 60 years old at the time of the survey, the legal age of retirement being 60 years in France in 2003. Our final sample thus comprises 2,570 observations.

In the PRI survey, respondents indicate when they would like to retire. We rely on this self-assessed question to study retirement intentions. Our empirical analysis is hence based on stated preferences. According to Louviere et al. (2000), such data can capture a much wider array of preference-driven behaviors than data on actual decisions. Over the last years, a large number of studies have examined the relationship between retirement expectations and subsequent behavior either at the individual or couple level (Bernheim, 1987, Benitez-Silva and Dwyer, 2005, Cobb-Clark and Stillman, 2009, Ho and Raymo, 2009). The main result is that stated preferences are relatively good predictors of retirement decisions, but people tend to retire generally earlier than planned.

According to the data, $55.6 \%$ of respondents intended to retire at exactly 60 . The proportion of interviewees who wished to leave the labor market after 60 was $24.7 \%$, which is slightly higher than the proportion of respondents expecting early retirement (19.6\%). On average, the mean intended age at retirement was 60.3 years. By comparison, the mean age at retirement in France in 2005 was 58.5 for men and 59.5 for women. While the difference between the intended and the current retirement ages may be explained by differences in retirement decisions among natives and migrants, it may also be due to the gap that often arises when comparing expectations and reality.

In Table 1, we provide a description of the selected variables to explain the intended age at retirement. There are more men than women in our sample $(59.8 \%$ instead of $40.2 \%)$, which is due to the focus on working individuals. $85.1 \%$ of respondents live in a couple, $73 \%$ of them are younger than 55 and $40 \%$ have only completed elementary school. In terms of occupation, the proportion of self-employed and executives is low compared to natives (respectively $8.5 \%$ and $7.3 \%$ ). Many migrants work either as employees among women (60.1\%) or blue-collar worker among men (55.3\%). Concerning the country of origin, $40.5 \%$ of the migrants come from Southern Europe, $28.1 \%$ from North Africa (33.9\% among men, but 19.6\% among women), and 6.3\% from Asia.

\section{Insert Table 1 here}

Let us focus on the health indicators. The first one is a self-assessed measure obtained from the following question: "at this moment, would you say that your health is: very good-good-fair - poor - very poor?". We define an ordered variable ranging from 1, corresponding to the "very poor" and 
"poor" health outcomes, to 4 when health is "very good" ${ }^{\text {" }}$. The second one is a dummy variable measuring whether the respondent has an illness or a disability causing troubles in everyday life. We find that $17.6 \%$ of the older migrants living in France reported a chronic disability. This proportion is slightly higher among women than among men (19.1\% instead of $16.6 \%)$. A similar difference by gender holds true when considering the self-assessment. On average, respectively $6 \%$ and $28.9 \%$ of respondents claim that their health status is respectively "very poor/poor" or "fair".

In Figure 1, we plot the intended retirement age as a function of health. These two outcomes are clearly not independent and we find that migrants in better health are more likely to postpone their decision to retire. For instance, the average intended age is 60.5 among migrants without chronic disability, but 59.6 among those with chronic disability (Figure 1A). In the same vein, respondents in poor health would like to retire at 59 instead of 61 for those in very good health (Figure 1B). We find very similar results for both men and women.

\section{Insert Figure 1}

As shown in Table 2, several other factors have an influence on retirement plans. On average, older migrants have a preference for late retirement (after 60). Highly educated interviewees also intend to postpone their retirement decision, the mean expected retirement age being 61.8 among those who have a University diploma. We find a similar pattern among executives. In both cases, the benefits of working longer should be much higher among respondents with high education or top occupation (they will receive higher wages on average). Conversely, there is no difference between employees and blue-collar workers.

\section{Insert Table 2 here}

The expected retirement age is an increasing function of the respondent's age at migration. Less than $14 \%$ of the respondents having migrated before 20 expected to retire after 60 .Finally, we observe a few differences depending on the migrant's country of origin. Those from Northern Europe were more likely to postpone their retirement decision, while migrants from Southern Europe had a preference for early retirement. While cultural effects may influence these differences by country of origin, they may also be due to differences in the observable labor market characteristics of the different groups of migrants living in France.

\section{Econometric specification}

We turn to an econometric analysis to study the influence of health on retirement. We estimate linear models to explain age at retirement as a function of health and other individual variables. For

\footnotetext{
${ }^{6}$ The outcomes "very poor" and "poor" are grouped into one category because of the limited number of respondents $(\mathrm{N}=25)$ reporting the former health status.
} 
the presentation, let $R$ be the intended retirement age. Ideally, we would like to estimate the following linear reduced-form specification for $R$ :

$$
R=\beta_{R} X_{R}+\gamma_{H} H^{*}+\varepsilon_{R}
$$

where $X_{R}$ is a set of exogenous variables influencing the retirement decision, $\beta_{R}$ is vector of coefficients to estimate, $H^{*}$ is a measure of "true" health, $\gamma_{H}$ is the associated health coefficient, and $\varepsilon_{R}$ is a random perturbation. The residual is expected to be normally distributed, with $E\left(\varepsilon_{R}\right)=0$ and $V\left(\varepsilon_{R}\right)=\sigma_{R}^{2}$. Under the assumption that $H^{*}$ is strictly exogenous in (1), then an unbiased estimator of the parameter of interest $\gamma_{H}$ would be given by an OLS estimation of the above specification since $R$ is a continuous outcome. Unfortunately, the exogeneity assumption of the health assessment is unlikely to hold.

As discussed in McGarry (2004), endogeneity may stem from several problems. Firstly, the "true" health status remains unobserved. The data set instead provides assessments of self-reported health that are likely to be affected by the justification bias. Respondents intending to retire earlier will tend to exaggerate their own health problems. Secondly, the current health status is itself shaped by the work trajectory (see Ettner, 1996, Wolff, 2005). Depending on the context, the ordered selfassessment may be more closely related to general health or it may pick up specific aspects of health related to employment. Thirdly, there may be some unobserved factors like preferences for leisure or rate of time discount that are likely to be correlated with both health and retirement plans.

It is hence difficult to know whether the estimation of $\gamma_{H}$ is either upward or downward biased. Different strategies have been proposed in empirical literature to solve these various problems. To avoid potential measurement errors due to the use of subjective health measures, Dwyer and Mitchell (1999) suggest using more objective variables such as the number of health conditions reported by respondents or indexes of activities of daily living when studying the retirement age profile. The role of the health variable in the retirement plan equation should be much lower with more objective measurements if measurement errors are substantial.

The potential endogeneity of the subjective health outcomes may also be taken into account through an instrumental variable estimation. However, the difficulty here consists of finding relevant instruments. Another strategy, considered by MacGarry (2004), is to focus on a sample of workers as the justification hypothesis is more likely among already retired individuals ${ }^{7}$. In her analysis, the subjective health assessments are introduced in an exogenous way when explaining the probability of continued work. Endogeneity is taken into account in the regression that covers changes in

\footnotetext{
${ }^{7}$ However, this selection of the sample under consideration does not totally avoid the problem of justification for those who do not really appreciate their current work.
} 
retirement expectations and changes in health since unobserved individual factors are dropped in the difference estimation ${ }^{8}$.

In what follows, we decide to follow the strategy of Dwyer and Mitchell (1999) more closely and rely on an instrumental variable approach to assess the effect of health on retirement plans. With regard to these authors, we explicitly account for the fact that our health assessments are discrete indicators. As the two subjective indicators are either binary or ordered, this means that estimates from 2SLS regressions are not appropriate. Specifically, we express the latent variable $H^{*}$ measuring true health in the following way:

$$
H^{*}=\beta_{H} X_{H}+\varepsilon_{H}
$$

where $X_{H}$ is a set of covariates explaining health, $\beta_{H}$ is vector of coefficients to estimate, and $\varepsilon_{H}$ is a random error term. By definition, $H^{*}$ remains unobserved.

The questionnaire instead includes two subjective health measurements, respectively chronic disability $H^{d}$ and self-rated health $H^{s}$. Let us first consider the case of disability. We then have $H^{d}=1$ when $H^{*}>0$ and $H^{d}=0$ otherwise. The model that we seek to estimate is:

$$
\left\{\begin{array}{c}
R=\beta_{R} X_{R}+\gamma_{H} H^{d}+\varepsilon_{R} \\
H^{*}=\beta_{H} X_{H}+\varepsilon_{H} \\
H^{d}=1 \text { if } H^{*}>0, H^{d}=0 \text { if } H^{*} \leq 0
\end{array}\right.
$$

We assume that the random perturbations $\varepsilon_{R}$ and $\varepsilon_{H}$ follow a bivariate normal distribution such that $\left(\varepsilon_{R}, \varepsilon_{H}\right) \sim N\left(0,0, \sigma_{R}^{2}, 1, \rho_{R H}\right)$, with $\rho_{R H}$ the correlation between the two random terms. Then, (3) defines a recursive, simultaneous-equation model comprising one continuous equation for retirement and one Probit equation for chronic disability. There are two groups for the observations of the sample depending on the value of $H^{d}$, and the recursive model is estimated using a maximum likelihood method.

The above specification can be extended to the case of an ordered health indicator. Self-reported subjective health $H^{S}$ takes values ranging from 1 ("very poor" or "poor" health) to 4 ("very good" health). The appropriate model is now:

$$
\left\{\begin{array}{c}
R=\beta_{R} X_{R}+\gamma_{H} H^{s}+\varepsilon_{R} \\
H^{*}=\beta_{H} X_{H}+\varepsilon_{H} \\
H^{s}=j \text { if } \mu_{j-1} \leq H<\mu_{j}, \text { with } j=1, \ldots, 4
\end{array}\right.
$$

This recursive specification now includes one continuous equation and one ordered Probit equation for the self-assessed health status. The threshold levels $\mu_{j}$ have to be estimated jointly with the parameters $\beta_{R}, \gamma_{H}$ and $\beta_{H}$. We set $\mu_{0}=-\infty, \mu_{4}=+\infty$ and the threshold level $\mu_{1}$ is normalized to 0 . The individual contribution to the likelihood depends on the value of $H^{S}$ and the simultaneous model is again estimated by a maximum likelihood technique.

\footnotetext{
${ }^{8}$ Unfortunately, the use of cross-sectional data in our context does not allow us to estimate fixed effects regressions.
} 
In such recursive models, the main difficulty is to find convenient instruments. The latter have to be correlated with the subjective health indicators, but they should have no influence on the retirement timing. Some authors have suggested the use of more objective measurements as instruments, like symptoms or diseases (Stern, 1989). While these conditions should by definition be highly correlated with the subjective health outcome, poor conditions may also be the result of labor participation because of work-related injury, for instance. Dwyer and Mitchell (1999) include as instruments whether the father and the mother are still living or not and also indicators of parental health (whether the father and the mother are dependent or not).

In what follows, we consider the three following instruments to identify the effect of health on retirement intentions. The first one is whether family members or friends help the respondent at home, either for personal health care, housework, meals, shopping or just to help out. Several studies have shown that individuals with health problems were much more likely to receive such informal care (Jellal and Wolff, 2002, Wolff and Dimova, 2009). A negative correlation between being in poor health and the receipt of informal support is then expected. Conversely, family help should have no direct influence on the expected retirement age.

The second set of instruments is given by two dummy variables indicating whether the father and the mother of the respondent are alive and in good health. Many studies have highlighted the importance of the intergenerational transmission of physical health from parents to children (see among others Currie and Moretti, 2007, and Coneus and Spiess, 2011), so that parental health should be positively related to the respondent's health. As emphasized in van Solinge and Henkens (2010), such parental effects have clearly something to do with perception of life expectancy. At the same time, middle-aged adults very often provide upstream transfers in the form of services to their elderly parents, especially when the latter are in poor health (Attias-Donfut et al., 2006). Thus, respondents with healthy parents may not have to retire in order to be a caregiver.

The last instrument is a dummy variable, equal to one when the respondent has spent at least one night in a hospital during the last twelve months ${ }^{10}$. A stay in a hospital is expected to be strongly positively correlated with health problems, while it should not be affected by the justification bias. It is difficult to believe a story where the respondent would accept to be hospitalized in order to have the intention to retire earlier. When turning to the data, we implement several tests to check the adequacy of the instruments for the health variables. Also, we choose to perform the instrumental variable regressions twice, the parental health variables being excluded in a first set of estimations.

\footnotetext{
${ }^{9}$ A difficulty is that respondents with parents in poor health may have to stop working in order to provide upstream care.

${ }^{10}$ Dwyer and Mitchell (1999) also used the number of nights spent in a hospital the previous year as an instrument.
} 


\section{Econometric results}

We attempt to get an unbiased estimate (net of endogeneity bias) of the heath impact on retirement plans. As a preliminary step, we treat chronic disability as a continuous outcome and turn to both OLS and linear IV regressions, whose results are shown in Table 3. The different control variables introduced in the regressions are gender, age, living as a couple, education, occupation, age at migration, number of children (respectively at home and outside), household income, constraint of liquidity, home ownership, and a set of country of origin dummies.

Insert Table 3 here

As shown in column $1 \mathrm{~A}$ of Table 3 , there is no gender difference in the intended retirement age. The intention to postpone retirement is more likely among older migrants. With respect to the $45-49$ age group, the expected retirement age increases by 0.83 year among the 50-54 age group and by 1.69 years among the 55-59 age group. Older respondents who have not left the labor market at the date of the survey had a preference for postponing retirement decisions. Living as a couple and the number of children living outside the home are two variables that are negatively correlated with retirement age, but these effects are not particularly significant. In France, respondents with several children need a lower number of annuities to get all their pension rights.

The intended retirement age is much higher among highly educated respondents and among executives. We find a negative relationship between retirement age and income (measured at the household level), although the relationship is not really significant at conventional level. It could be that richer respondents can afford to retire earlier. A similar negative effect is found among homeowners, this variable being considered here as a proxy for wealth. Finally, there are no clear differences by country of origin; the case of Asian migrants who intended to retire later is nevertheless an exception ${ }^{11}$.

As shown in columns $1 \mathrm{~A}$ and 2 of Table 3 , there is a negative correlation between health and expected retirement age among migrants. For instance, respondents intended to leave the labor market 0.68 year earlier when they reported a chronic disability. The marginal effect is even larger when considering the self-assessed health outcome. Being in poor or very poor health decreases the retirement age by 1.65 years, while the reduction is about 0.5 year when considering the good or fair health status (the reference point being very good health) ${ }^{12}$. Of course, these preliminary results

\footnotetext{
${ }^{11}$ Respondents from Asia intend to postpone retirement by 0.72 year on average, but it should be noted that this effect is only significant at the 10 percent level.

${ }^{12}$ Among respondents who have migrated during their youth, it could be argued that health problems should have less influence on retirement intentions since these cases are more related to family migrations than to labor migrations. We have then estimated separate regressions respectively for those arrived in France before 21 and those arrived after 20. We find very similar coefficients for the dummy related to chronic disease, respectively 0.664 for the dummy related to chronic disease in the former group, while the health coefficient is nearly the same $(-0.678)$ among the group of migrants who have migrated after 20 (the corresponding estimates are available upon request).
} 
concerning the role of the health outcome have to be interpreted with caution because of potential endogeneity.

An interesting feature of the OLS regressions is that they indicate the respective influence of health problems (under the exogeneity assumption) and economic factors on retirement plans. For that purpose, we turn to the decomposition methodology proposed in Fields (2004). From the linear model $R=\beta_{R} X_{R}+\gamma_{H} H+\varepsilon_{R}\left(H=H^{d}, H^{s}\right)$ and assuming that there are $K$ exogenous regressors in $X_{K}$ indexed by $k$ (with $k=1, \ldots, K$ ), then the variance of the dependent variable $R$ can be decomposed in the following way:

$$
\operatorname{var}(R)=\sum_{k} \operatorname{cov}\left(\beta_{R} X_{R}, R\right)+\operatorname{cov}\left(\gamma_{H} H, R\right)+\operatorname{cov}\left(\varepsilon_{R}, R\right)
$$

We then deduce the relative contribution of the covariates and the residual from:

$$
\sum_{k} s\left(X_{k}\right)+s(H)+s(\varepsilon)=100 \%
$$

with $s\left(X_{R}\right)=\operatorname{cov}\left(\beta_{R} X_{R}, R\right) / \operatorname{var}(R), s(H)=\operatorname{cov}\left(\gamma_{H} H, R\right) / \operatorname{var}(R)$ and $s(\varepsilon)=\operatorname{cov}(\varepsilon, R) / \operatorname{var}(\mathrm{R})$. The first two terms on the left-hand side of (6) sum exactly to the R-squared, so that $s\left(X_{R}\right)$ and $s(H)$ provide respectively the weight of each regressor $k$ and of the health status. Results from the decompositions are in Table 4, respectively on the whole sample and by gender.

\section{Insert Table 4 here}

According to the PRI data, the role of poor health remains modest when explaining retirement intentions among migrants living in France. Reporting chronic disability accounts for about $5 \%$ of the intended retirement age. In comparison, the contribution of economic factors is much higher. The relative weight of education, occupation and age at migration amounts to $22.5 \%, 8.3 \%$ and $23.4 \%$ respectively, the most influential factor being the respondent's age (25.6\%). An interesting result is the difference between the two health measurements. The contribution of the self-assessed health outcome is larger (8.8\%) than that of chronic disability $(5.3 \%)$, but the role played by the health status remains limited in both cases. This may be due to the fact that the self-assessed measurement is more likely to be contaminated by some justification bias ${ }^{13}$.

Let us now turn to the IV estimates. While the OLS coefficient of chronic disability is equal to -0.681 in the retirement age equation (column $1 \mathrm{~A}$ ), its value is about two times higher $(-1.503)$ once endogeneity is taken into account and it is still significant at the five percent level (column 1B). This suggests that the role of health is underestimated under the exogeneity assumption. The same negative effect of health problems on retirement plans holds true with the self-rated assessment. In column (2A), we first estimated a retirement equation with the self-assessed assessment as a continuous regressor. Under the exogeneity assumption, the OLS health coefficient is positive, equal

\footnotetext{
${ }^{13}$ This explanation would be consistent with the gender differences shown in Table 4. The contribution of the self-reported health outcome is much higher among men than among women ( $11.1 \%$ instead of $5.8 \%)$.
} 
to 0.392 . We then estimated an IV regression and find an instrumented coefficient of 0.880 for the self-reported health assessment, which is again about twice as high (column 2B, Table 3).

Two additional comments are in order. First, we performed some statistical tests to check the relevance of the two instruments, i.e. any stay in a hospital during last year and receipt of help from family members or friends during last year. On the one hand, an F-test indicates that the two instruments are strongly correlated with the health outcome (either chronic disability or self-rated health). On the other hand, the Hansen over-identification test is not significant at conventional levels. This suggests that the instruments have the desirable properties. Secondly, we found that the endogeneity-corrected health coefficient does not really depend on the sets of selected instruments. When adding the parental variables in the first-stage health regression (both father and mother alive and in good health), we found a value of -1.545 for the chronic disability coefficient (column $1 \mathrm{C}$ ) and of 0.910 for the self-reported health assessment (column 2C).

We then turned to the estimation of the recursive models given by (3) and (4), meaning that we explicitly accounted for the binary (respectively ordered) nature of chronic disability (respectively self-rated) status. The corresponding results are in Table 5. In column (1), the endogenous disability outcome is thus explained by a Probit regression. Reporting a chronic disability is more likely among the older age group of migrants (55-59). Having health problems is less likely among highly educated migrants and among executives and intermediary (at the 10 percent level). The probability of chronic disability is higher for those who are liquidity constrained, and it strongly increases with a stay in a hospital and with help from outside during the last year. The main result of the recursive model is that the chronic disability variable (treated in an endogenous way) is significantly negative in the retirement age regression ${ }^{14}$.

\section{Insert Table 5 here}

In column (2) of Table 5, we estimated the recursive model with one continuous equation for retirement plans and one ordered Probit equation for the self-reported health outcome. A positive coefficient between the self-rated assessment and retirement age is now expected. We find a value of 0.963 for the endogenous health outcome in the retirement equation, which is only significant at the 10 percent level. This lack of significance is clearly not due to the use of poor instrumental variables. As shown in Table 5, the subjective ordered indicator is strongly negatively correlated with a stay in a hospital and with outside help, while the health outcome is better when respondents have their fathers alive and in good health. An explanation could be that the effect of health on retirement

\footnotetext{
${ }^{14}$ The correlation between the residuals of the chronic disability and retirement age equations is positive and significant.
} 
is highly non-linear: the decision to leave the labor market early would essentially stem from poor health situations ${ }^{15}$.

In the recursive model described in column (3), the focus is on poor health status since the health outcome under consideration is now a dummy variable equal to one when the respondent feels either in very poor, poor or fair health. First, the determinants of the self-assessed poor health status are very similar to those of chronic disease. On average, respondents in poor health are older and less educated, they have lower levels of income and are more often liquidity constrained. Secondly, the data shows that it is really the poor health situations that motivate the decision to retire early among migrants, since the endogenous health variable has now a negative impact (significant at the 1 percent level) in the retirement plans equation.

\section{Conclusion}

In France, the proportion of migrants aged 40 years old and above has increased more than in the rest of the population over the past decades. Many immigrants who arrived in France during the 60s are now about to reach retirement age. A few studies, essentially dealing with US data, have recently shown that being in poor health had a positive effect on the probability of early departure from the labor market. However, nothing is really known so far concerning the potential influence of health on retirement plans among the migrant population.

In this paper, we have used detailed data on immigrants living in France collected in 2003 to study the role of health on early retirement intentions. Estimation of recursive models allows us to account for both endogeneity and discreteness of the health status in the retirement age equation. Our main results are twofold. On the one hand, we find that early retirement is positively influenced by poor health among the migrant population in France. This pattern is independent of the measurement of health (either chronic disease or poor/fair self-assessed health) and does not support the justification hypothesis. On the other hand, results from a Field's decomposition suggest that the subjective health status has little influence on retirement plans.

Several interpretations may come to mind when comparing our results to those from previous studies. For instance, McGarry (2004) finds a much higher contribution of subjective health outcomes on retirement decisions in the US. A first possibility is that migrants are essentially in the host country for labor market considerations. If there is a substantial wage gap between host and origin countries, then migrants could be tempted to work longer (and thus to retire later) in order to

\footnotetext{
${ }^{15}$ By definition, the ordered Probit equation related to the health outcome is itself non-linear. However, this specification does not really account for the fact that there may be no difference in retirement age when respondents are either in good health or in very good health.
} 
accumulate more money before returning or not to their country of origin ${ }^{16}$. As a consequence, they would be less sensitive to health considerations. A related explanation is that depending on their age on arrival in France, migrants have not necessarily contributed to the pension system for enough years at 60 years of age. Hence, they would have to postpone their retirement decisions in order to avoid an excessive pension reduction.

Another possibility could be due to differences in preferences for retirement between migrants and natives. In many poor countries, there is no formal pension scheme for the working population and many respondents interviewed in the PRI survey (recall that they are first-generation immigrants) have certainly seen their parents working to a very old age. Unfortunately, the available data does not allow us to investigate the relevance of these various assumptions since there is no native control group in our data. As the ageing of the immigrant population is a strong concern among all developed countries, it would be of interest to compare the retirement plans of migrants and natives and to assess the respective role of health on retirement age expectations in both population groups.

\footnotetext{
${ }^{16}$ This incentive does not depend on the intended location at retirement, since migrants would be even richer if they decided to return to their origin country where the cost of living is presumably lower.
} 


\section{References}

Attias-Donfut C., Tessier P., Wolff F.C., (2005), "Immigrants at retirement", Retraite et Société, Special issue, pp. 5-39.

Attias-Donfut C., Ogg J., Wolff F.C., (2005), "European patterns of intergenerational financial and time transfers", European Journal of Aging, vol. 2, pp. 161-173.

Bazzoli G.J, (1985), "The early retirement decision: New empirical evidence on the influence of health", Journal of Human Resources, vol. 20, pp. 215-234.

Benitez-Silva H., Dwyer D.S., (2005), "The rationality of retirement expectations and the role of new information", Review of Economics and Statistics, vol. 87, pp. 587-592.

Bernheim B.D., (1987), "The timing of retirement: A comparison of expectations and realizations", NBER Working Paper, $\mathrm{n}^{\circ} 2291$.

Bound J., (1991), "Self-reported versus objective measures of health in retirement models", Journal of Human Resources, vol. 26, pp. 106-138.

Brugiavini A., (2001), "Early retirement in Europe", European Review, vol. 9, pp. 501-515.

Cobb-Clark D.A., Stillman S., (2009), "The retirement expectations of middle-aged individuals", Economic Record, vol. 85, pp. 146-163.

Coneus K., Spiess K., (2011), "The intergenerational transmission of health in early childhood. Evidence from the German Socio-Economic Panel", Economics and Human Biology, forthcoming.

Currie J., Moretti E., (2007), "Biology as destiny? Short and long-run determinants of intergenerational transmission of birth weight", Journal of Labor Economics, vol. 25, pp. 231-264.

Dwyer D.S., Mitchell O.S., (1999), "Health problems as determinants of retirement: Are self-rated measures endogenous ?", Journal of Health Economics, vol. 18, pp. 173-193.

Ettner S.L., (1996), "New evidence on the relationship between income and health", Journal of Health Economics, vol. 15, pp. 67-85.

Fields, G. (2004), "Regression-Based Decompositions: A New Tool for Managerial Decision-Making", Mimeo, Cornell University.

Heitmueller A., (2007), "The chicken or the egg ? Endogeneity in labour market participation of informal carers in England", Journal of Health Economics, vol. 26, pp. 536-559.

Ho J.-H., Raymo J.M., (2009), "Dual-worker couples expectations and realization of joint retirement among dual-worker couples", Research on Aging, vol. 31, pp. 153-179.

Jellal M., Wolff F.C., (2002), "Cultural evolutionary altruism: Theory and evidence", European Journal of Political Economy, vol. 18, pp. 241-262.

Lalonde R.J., Topel R.H., (1997), "Economic impact of international migration and the economic performance of migrants", in Rosenzweig M.R., Stark O., eds., Handbook of Population and Family Economics, Elsevier, North Holland, vol. 1B, pp. 799-850.

Lazear E.P., (1986), "Retirement from the labor force", in Ashenfelter O., Layard R., eds., Handbook of Labor Economics, Elsevier, North Holland, vol. 1, pp. 305-355.

Louviere J., Hensher D., Swait J., (2002), Stated Choice Methods, Cambridge University Press, Cambridge.

Lumsdaine R.L., Mitchell O.S., (1999), "New developments in the economic analysis of retirement", in Ashenfelter O., Card D., eds., Handbook of Labor Economics, Elsevier, North Holland, vol. 3, pp. 32613307. 
McDonald J.T., Kennedy S., (2004), "Insights into the "healthy immigrant effect": Health status and health service use of immigrants to Canada", Social Science and Medicine, vol. 59, pp. 1613-1627.

McGarry K., (2004), "Health and retirement: Do changes in health affect retirement expectations?", Journal of Human Resources, vol. 39, pp. 624-648.

Siegrist J., Wahrendorf M., von dem Knesebeck O., Jürges H., Börsch-Supan A., (2006), “Quality of work, well-being and intended early retirement of older employees. Baseline results from the Share Study", European Journal of Public Health, vol. 17, pp. 62-68.

van Solinge H., Henkens K., (2010), "Living longer, working longer? The impact of subjective life expectancy on retirement intentions and behaviour", European Journal of Public Health, vol. 20, pp. 47-51.

Stern S., (1989), "Measuring the effect of disability on labor force participation", Journal of Human Resources, vol. 24, pp. 361-395.

Wolff F.C., (2005), "Disability and labor supply during economic transition: Evidence from Bulgaria", Labour, vol. 19, pp. 303-341.

Wolff F.C., Dimova R., (2009), “Upstream transfers and the donor's labour supply: Evidence from migrants living in France", Manchester School, vol. 77, pp. 204-224. 
Figure 1. The relationship between health and expected age at retirement A. Chronic disability
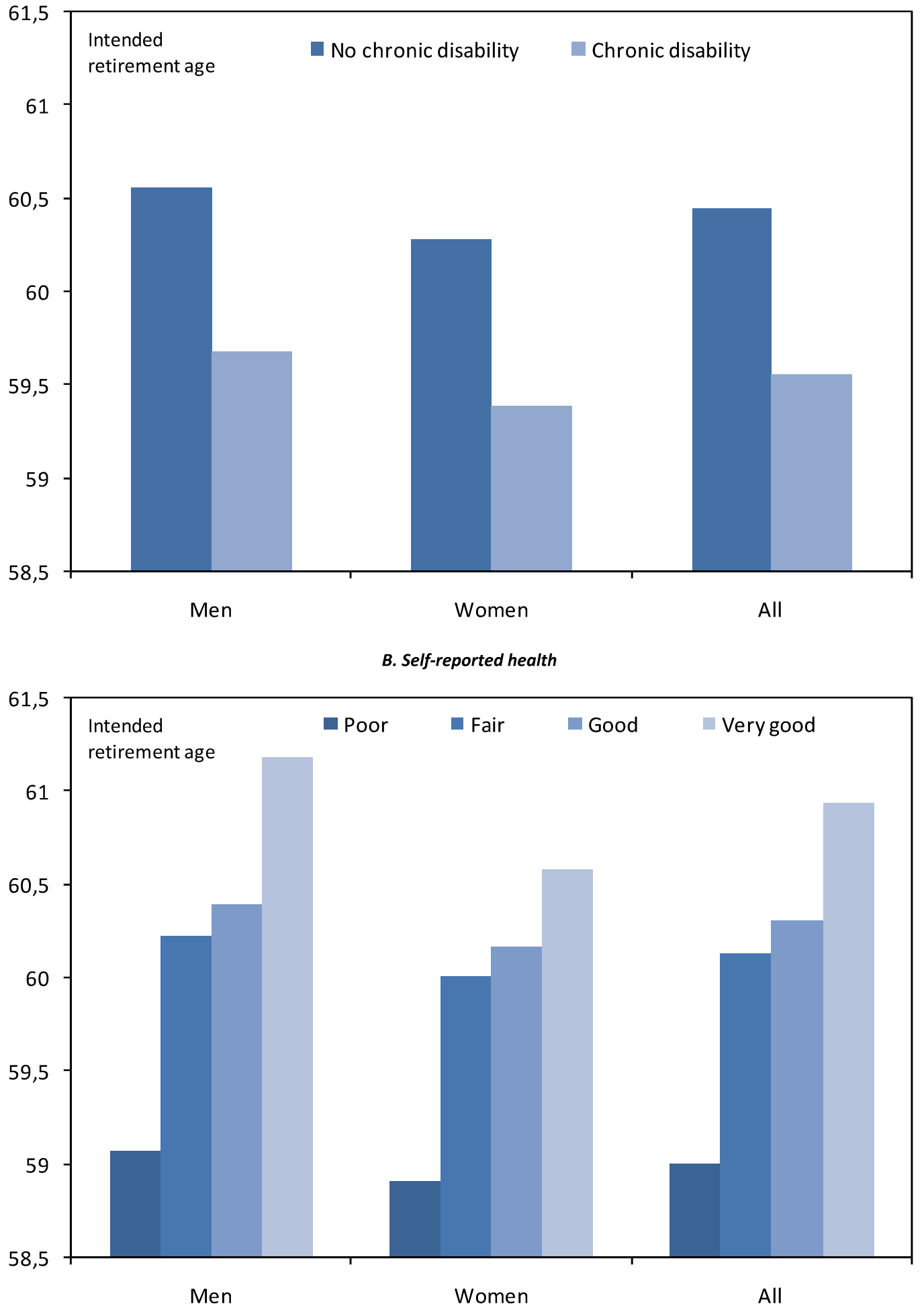

Source: Survey PRI 2003. 
Table 1. Descriptive statistics of the sample

\begin{tabular}{|c|c|c|c|c|}
\hline Variables & & Men & Women & All \\
\hline \multirow[t]{3}{*}{ Expected retirement age } & Before 60 & 0.191 & 0.205 & 0.196 \\
\hline & At 60 & 0.554 & 0.560 & 0.556 \\
\hline & After 60 & 0.256 & 0.234 & 0.247 \\
\hline Female & & 0.000 & 1.000 & 0.402 \\
\hline \multirow[t]{3}{*}{ Age } & $45-49$ & 0.344 & 0.405 & 0.368 \\
\hline & $50-54$ & 0.377 & 0.353 & 0.367 \\
\hline & $55-59$ & 0.279 & 0.242 & 0.264 \\
\hline In couple & & 0.924 & 0.743 & 0.851 \\
\hline \multirow{5}{*}{ Education } & Primary & 0.391 & 0.404 & 0.396 \\
\hline & BEPC & 0.166 & 0.176 & 0.170 \\
\hline & BEP-CAP & 0.165 & 0.130 & 0.151 \\
\hline & Baccalaureate & 0.088 & 0.097 & 0.091 \\
\hline & High education & 0.191 & 0.193 & 0.191 \\
\hline \multirow[t]{5}{*}{ Occupation } & Self-employed & 0.116 & 0.039 & 0.085 \\
\hline & Executive & 0.088 & 0.049 & 0.073 \\
\hline & Intermediary & 0.157 & 0.145 & 0.153 \\
\hline & Employee & 0.085 & 0.601 & 0.292 \\
\hline & Worker & 0.553 & 0.166 & 0.398 \\
\hline Chronic disability & Yes & 0.166 & 0.191 & 0.176 \\
\hline \multirow[t]{4}{*}{ Self-reported health } & Very poor - poor & 0.057 & 0.064 & 0.060 \\
\hline & Fair & 0.277 & 0.307 & 0.289 \\
\hline & Good & 0.488 & 0.450 & 0.472 \\
\hline & Very good & 0.178 & 0.179 & 0.179 \\
\hline \multirow[t]{4}{*}{ Age at migration } & $0-9$ & 0.129 & 0.148 & 0.137 \\
\hline & $10-19$ & 0.287 & 0.230 & 0.264 \\
\hline & $20-29$ & 0.454 & 0.462 & 0.458 \\
\hline & 30 and above & 0.130 & 0.160 & 0.142 \\
\hline Income (log) & & 9.991 & 9.883 & 9.948 \\
\hline Liquidity constrained & & 0.142 & 0.127 & 0.136 \\
\hline Home owner & & 0.708 & 0.683 & 0.698 \\
\hline \multirow[t]{8}{*}{ Country of origin } & Northern Europe & 0.051 & 0.092 & 0.068 \\
\hline & Southern Europe & 0.380 & 0.441 & 0.405 \\
\hline & Eastern Europe & 0.027 & 0.072 & 0.045 \\
\hline & Northern Africa & 0.339 & 0.196 & 0.281 \\
\hline & Southern Africa & 0.080 & 0.078 & 0.079 \\
\hline & America & 0.018 & 0.033 & 0.024 \\
\hline & Middle & 0.044 & 0.023 & 0.035 \\
\hline & Asia & 0.061 & 0.065 & 0.063 \\
\hline Number of observations & & 1538 & 1032 & 2570 \\
\hline
\end{tabular}


Table 2. Description of the sample, by expected age at retirement

\begin{tabular}{|c|c|c|c|c|c|}
\hline \multicolumn{2}{|l|}{ Variables } & \multicolumn{3}{|c|}{ Expected retirement age (in \%) } & \multirow{2}{*}{$\begin{array}{l}\text { Mean expected } \\
\text { retirement age }\end{array}$} \\
\hline & & \multirow{2}{*}{$\frac{\text { Before } 60}{20.5}$} & \multirow{2}{*}{$\frac{\text { At } 60}{56.0}$} & \multirow{2}{*}{$\frac{\text { After } 60}{23.5}$} & \\
\hline Female & & & & & 60.1 \\
\hline Age & $45-49$ & 26.9 & 52.6 & 20.5 & 59.6 \\
\hline & $50-54$ & 19.7 & 57.0 & 23.3 & 60.4 \\
\hline & $55-59$ & 9.4 & 58.0 & 32.6 & 61.2 \\
\hline In couple & & 20.6 & 55.5 & 23.9 & 60.2 \\
\hline \multirow[t]{5}{*}{ Education } & Primary & 20.4 & 61.5 & 18.1 & 59.9 \\
\hline & $\mathrm{BEPC}$ & 22.0 & 57.7 & 20.4 & 59.9 \\
\hline & BEP-CAP & 26.8 & 57.7 & 15.5 & 59.6 \\
\hline & Baccalaureate & 18.3 & 50.6 & 31.1 & 60.6 \\
\hline & High education & 11.0 & 42.5 & 46.5 & 61.8 \\
\hline \multirow[t]{5}{*}{ Occupation } & Self-employed & 15.6 & 55.5 & 28.9 & 60.7 \\
\hline & Executive & 6.4 & 42.3 & 51.3 & 62.2 \\
\hline & Intermediary & 21.2 & 50.3 & 28.6 & 60.5 \\
\hline & Employee & 22.1 & 56.3 & 21.6 & 59.9 \\
\hline & Worker & 20.6 & 59.7 & 19.8 & 60.1 \\
\hline \multirow[t]{4}{*}{ Age at migration } & $0-9$ & 28.5 & 57.8 & 13.7 & 59.3 \\
\hline & $10-19$ & 26.0 & 60.6 & 13.4 & 59.6 \\
\hline & $20-29$ & 16.8 & 55.2 & 28.1 & 60.5 \\
\hline & 30 and above & 8.8 & 45.8 & 45.5 & 61.8 \\
\hline \multirow[t]{4}{*}{ Income } & Quartile 1 & 16.4 & 58.7 & 24.9 & 60.5 \\
\hline & Quartile 2 & 21.3 & 55.8 & 22.9 & 60.1 \\
\hline & Quartile 3 & 20.6 & 58.9 & 20.6 & 60.0 \\
\hline & Quartile 4 & 20.4 & 49.1 & 30.5 & 60.5 \\
\hline \multicolumn{2}{|c|}{ Liquidity constrained } & 21.8 & 55.3 & 22.9 & 60.1 \\
\hline \multicolumn{2}{|c|}{ Home owner } & 20.7 & 56.1 & 23.2 & 60.2 \\
\hline \multirow[t]{8}{*}{ Country of origin } & Northern Europe & 12.6 & 44.3 & 43.1 & 61.4 \\
\hline & Southern Europe & 23.8 & 61.1 & 15.2 & 59.6 \\
\hline & Eastern Europe & 15.7 & 50.4 & 33.9 & 60.9 \\
\hline & Northern Africa & 19.1 & 54.6 & 26.3 & 60.4 \\
\hline & Southern Africa & 19.1 & 52.0 & 28.9 & 60.3 \\
\hline & America & 17.7 & 32.3 & 50.0 & 62.0 \\
\hline & Middle & 14.3 & 56.0 & 29.7 & 60.7 \\
\hline & Asia & 10.6 & 54.7 & 34.8 & 61.6 \\
\hline \multicolumn{2}{|l|}{ Total } & 19.7 & 55.6 & 24.7 & 60.3 \\
\hline
\end{tabular}

Source: Survey PRI 2003. 
Table 3. OLS and IV estimates of expected age at retirement

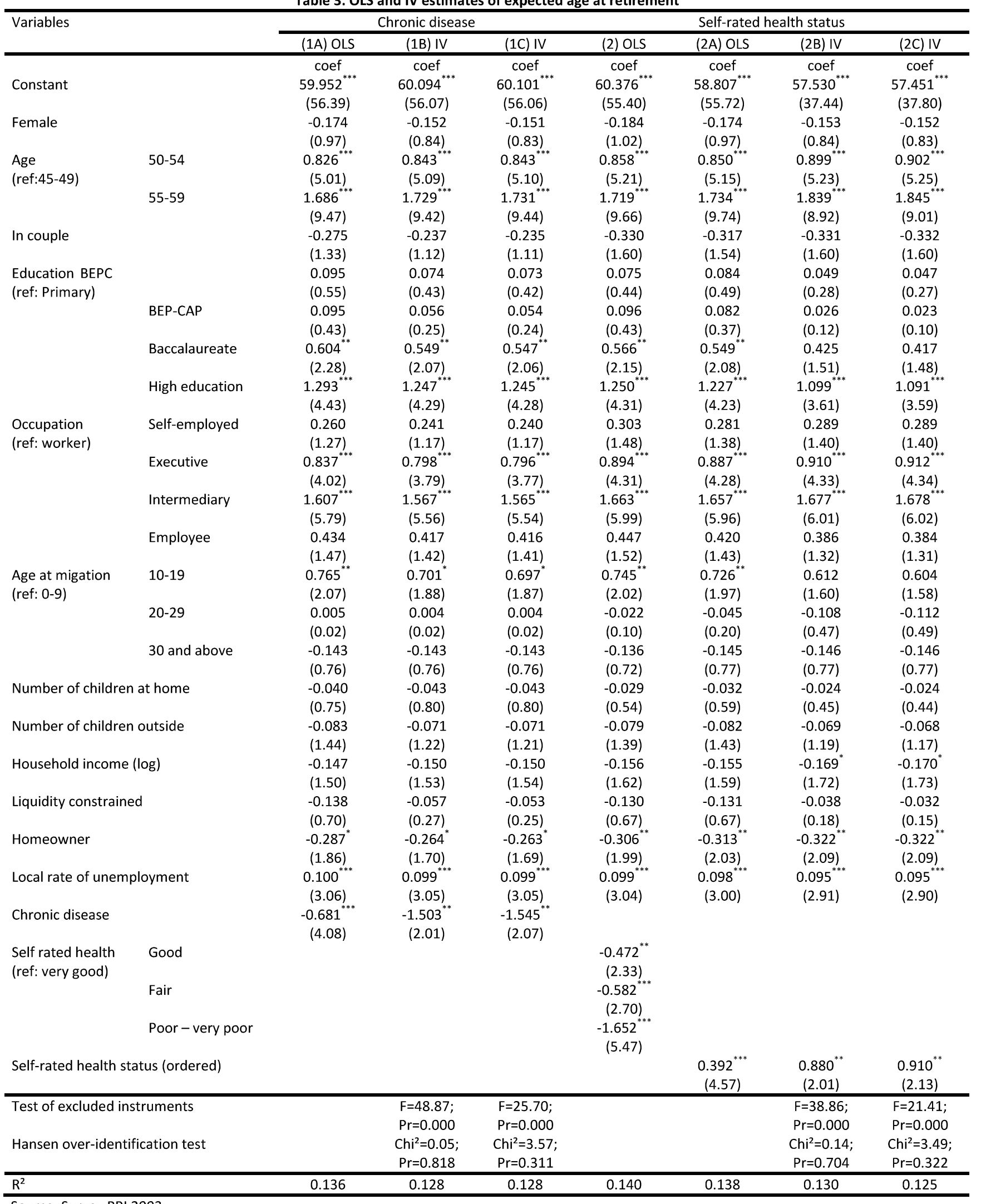

Source: Survey PRI 2003.

Notes: Estimates from OLS and IV regressions, with robust standard errors. The sample includes 2570 observations. Absolute values of $t$ statistics are in parentheses, significance levels being respectively $1 \%\left({ }^{* * *}\right), 5 \%\left(\left(^{* *}\right)\right.$ and $10 \%\left({ }^{*}\right)$. In (1B) and (2B), the two instruments are "any stay in a hospital during last year" and "receipt of help from family members or friends during last year". In (1C) and (2C), the set of instruments includes the two previous ones along with two variables indicating whether the father and the mother are alive and in good health. The different regressions also include a set of country of origin dummies. 
Table 4. Fields's decomposition of expected age at retirement

\begin{tabular}{|c|c|c|c|c|c|c|}
\hline \multirow[t]{2}{*}{ Variables } & \multicolumn{3}{|c|}{ (1) } & \multicolumn{3}{|c|}{ (2) } \\
\hline & Men & Women & All & Men & Women & All \\
\hline Gender & - & - & $0.7 \%$ & - & - & $0.8 \%$ \\
\hline In couple & $-1.2 \%$ & $2.1 \%$ & $1.1 \%$ & $-0.9 \%$ & $2.3 \%$ & $1.3 \%$ \\
\hline Education & $20.0 \%$ & $23.3 \%$ & $22.0 \%$ & $18.8 \%$ & $22.4 \%$ & $20.6 \%$ \\
\hline Occupation & $29.7 \%$ & $18.5 \%$ & $23.5 \%$ & $28.4 \%$ & $19.3 \%$ & $23.4 \%$ \\
\hline Number of children outside & $0.0 \%$ & $0.2 \%$ & $0.1 \%$ & $0.0 \%$ & $0.2 \%$ & $0.1 \%$ \\
\hline Income & $-0.2 \%$ & $-0.2 \%$ & $-0.2 \%$ & $-0.2 \%$ & $-0.2 \%$ & $-0.2 \%$ \\
\hline Liquidityconstrained & $0.0 \%$ & $0.8 \%$ & $0.2 \%$ & $0.0 \%$ & $0.8 \%$ & $0.2 \%$ \\
\hline Homeowner & $1.0 \%$ & $2.4 \%$ & $1.5 \%$ & $1.1 \%$ & $2.5 \%$ & $1.6 \%$ \\
\hline Local rate of unemployment & $1.9 \%$ & $3.0 \%$ & $2.3 \%$ & $1.8 \%$ & $3.0 \%$ & $2.2 \%$ \\
\hline Total & $100.0 \%$ & $100.0 \%$ & $100.0 \%$ & $100.0 \%$ & $100.0 \%$ & $100.0 \%$ \\
\hline
\end{tabular}

Source: Survey PRI 2003. 
Table 5. Estimates of retirement age-health simultaneous recursive models

\begin{tabular}{|c|c|c|c|c|c|c|c|}
\hline \multirow[t]{2}{*}{ Variables } & & \multicolumn{2}{|c|}{ (1) } & \multicolumn{2}{|c|}{ (2) Ordered self-rated health } & \multicolumn{2}{|c|}{ (3) Self-rated poor health } \\
\hline & & $\begin{array}{l}\text { Retirement: } \\
\text { Continuous }\end{array}$ & $\begin{array}{l}\text { Chronic disease: } \\
\text { Probit model }\end{array}$ & $\begin{array}{l}\text { Retirement: } \\
\text { Continuous }\end{array}$ & $\begin{array}{c}\text { Self-rated } \\
\text { health:Ordered } \\
\text { Probit }\end{array}$ & $\begin{array}{l}\text { Retirement: } \\
\text { Continuous }\end{array}$ & $\begin{array}{c}\text { Poor/fair self-rated } \\
\text { health:Probit }\end{array}$ \\
\hline \multirow{3}{*}{\multicolumn{2}{|c|}{ Constant }} & coef & coef & coef & coef & coef & coef \\
\hline & & $60.333^{* * *}$ & $-0.826^{*}$ & $57.294^{* * *}$ & & $59.921^{* * *}$ & 0.118 \\
\hline & & $(55.76)$ & $(1.76)$ & (31.23) & & $(56.68)$ & $(0.28)$ \\
\hline \multicolumn{2}{|l|}{ Female } & -0.119 & 0.056 & -0.151 & -0.036 & -0.176 & 0.114 \\
\hline \multirow[t]{2}{*}{ Age } & $50-54$ & $0.870^{* * *}$ & 0.069 & $0.903^{* * *}$ & $-0.120^{* *}$ & $0.823^{* * *}$ & 0.083 \\
\hline & & $(5.15)$ & $(0.90)$ & $(5.11)$ & $(2.26)$ & $(5.02)$ & $(1.25)$ \\
\hline \multirow[t]{2}{*}{ (ref:45-49) } & $55-59$ & $1.805^{* * *}$ & $0.190^{* *}$ & $1.849^{* * *}$ & $-0.259^{* * *}$ & $1.674^{* * *}$ & $0.311^{* * *}$ \\
\hline & & $(9.35)$ & $(2.16)$ & $(8.25)$ & $(4.23)$ & $(9.45)$ & (4.10) \\
\hline \multirow[t]{2}{*}{ In couple } & & -0.177 & 0.126 & -0.336 & 0.071 & -0.279 & -0.045 \\
\hline & & $(0.81)$ & $(1.34)$ & $(1.61)$ & $(1.02)$ & $(1.35)$ & $(0.54)$ \\
\hline \multicolumn{2}{|l|}{ Education BEPC } & 0.042 & -0.078 & 0.042 & 0.089 & 0.097 & -0.028 \\
\hline & & $(0.23)$ & $(0.90)$ & $(0.23)$ & $(1.37)$ & $(0.56)$ & $(0.37)$ \\
\hline \multirow{5}{*}{ (ref: Primary) } & & $(0.02)$ & $(1.58)$ & $(0.05)$ & (1.78) & $(0.44)$ & (1.76) \\
\hline & Baccalaureate & $0.463^{*}$ & $-0.234^{*}$ & 0.403 & $0.332^{* * *}$ & $0.610^{* *}$ & $-0.381^{* * *}$ \\
\hline & & (1.68) & $(1.84)$ & $(1.36)$ & (3.90) & $(2.31)$ & (3.46) \\
\hline & High education & $1.174^{* * *}$ & $-0.232^{*}$ & $1.076^{* * *}$ & $0.346^{* * *}$ & $1.298^{* * *}$ & $-0.448^{* * *}$ \\
\hline & & (3.92) & $(1.88)$ & $(3.36)$ & (4.34) & $(4.47)$ & $(4.20)$ \\
\hline \multirow[t]{2}{*}{ Occupation } & Self-employed & 0.210 & -0.084 & 0.290 & -0.030 & 0.265 & -0.014 \\
\hline & & $(0.96)$ & $(0.81)$ & $(1.40)$ & $(0.40)$ & $(1.30)$ & $(0.15)$ \\
\hline \multirow[t]{6}{*}{ (ref: worker) } & Executive & $0.735^{* * *}$ & $-0.193^{*}$ & $0.917^{* * *}$ & -0.075 & $0.844^{* * *}$ & 0.065 \\
\hline & & (3.29) & $(1.85)$ & $(4.34)$ & $(1.01)$ & $(4.08)$ & $(0.68)$ \\
\hline & Intermediary & $1.501^{* * *}$ & $-0.250^{*}$ & $1.683^{* * *}$ & -0.051 & $1.614^{* * *}$ & 0.067 \\
\hline & & $(5.14)$ & $(1.91)$ & $(6.00)$ & $(0.56)$ & $(5.84)$ & $(0.57)$ \\
\hline & Employee & 0.391 & -0.090 & 0.379 & 0.081 & 0.435 & $-0.172^{*}$ \\
\hline & & (1.30) & $(0.74)$ & $(1.28)$ & $(0.94)$ & $(1.47)$ & $(1.66)$ \\
\hline \multirow[t]{2}{*}{ Age at migation } & $10-19$ & 0.599 & $-0.447^{* *}$ & 0.593 & $0.314^{* * *}$ & $0.773^{* *}$ & $-0.483^{* * *}$ \\
\hline & & (1.55) & $(2.44)$ & $(1.50)$ & (3.01) & (2.10) & (3.05) \\
\hline (ref: 0-9) & $20-29$ & 0.005 & 0.019 & -0.121 & $0.175^{* *}$ & 0.004 & $-0.304^{* * *}$ \\
\hline & & $(0.73)$ & $(0.29)$ & $(0.76)$ & $(0.26)$ & $(0.76)$ & $(0.60)$ \\
\hline Number of childr & at home & -0.048 & -0.016 & -0.023 & -0.022 & -0.040 & 0.021 \\
\hline & & $(0.86)$ & $(0.63)$ & $(0.42)$ & (1.19) & $(0.74)$ & $(0.99)$ \\
\hline Number of childr & outside & -0.053 & 0.041 & -0.068 & -0.032 & -0.084 & $0.048^{* *}$ \\
\hline & & $(0.90)$ & $(1.58)$ & (1.14) & $(1.64)$ & $(1.47)$ & (2.03) \\
\hline Household incom & og) & -0.156 & -0.027 & $-0.169^{*}$ & $0.050^{*}$ & -0.145 & $-0.073^{* *}$ \\
\hline & & $(1.56)$ & $(0.67)$ & $(1.72)$ & (1.65) & (1.49) & (1.99) \\
\hline Liquidity constrai & & 0.071 & $0.328^{* * *}$ & -0.022 & $-0.225^{* * *}$ & -0.147 & $0.262^{* * *}$ \\
\hline & & $(0.32)$ & (3.81) & $(0.09)$ & (3.31) & $(0.74)$ & (3.36) \\
\hline Homeowner & & -0.227 & 0.098 & $-0.323^{* *}$ & 0.040 & $-0.291^{*}$ & -0.079 \\
\hline & & $(1.42)$ & $(1.37)$ & $(2.08)$ & $(0.78)$ & (1.89) & $(1.28)$ \\
\hline Local rate of une & loyment & $0.098^{* * *}$ & -0.015 & $0.095^{* * *}$ & 0.015 & $0.100^{* * *}$ & -0.017 \\
\hline & & $(2.95)$ & $(0.98)$ & $(2.88)$ & (1.32) & (3.08) & $(1.22)$ \\
\hline Any stay in a hos & during last year & & $0.504^{* * *}$ & & $-0.412^{* * *}$ & & $0.370^{* * *}$ \\
\hline & & & $(5.60)$ & & $(5.56)$ & & (4.38) \\
\hline Receipt of help fr & family members/friends & & $0.551^{* * *}$ & & $-0.352^{* * *}$ & & $0.359^{* * *}$ \\
\hline & & & $(7.52)$ & & $(6.42)$ & & $(5.62)$ \\
\hline Father alive and $\mathrm{i}$ & ood health & & $-0.142^{*}$ & & $0.157^{* * *}$ & & $-0.130^{*}$ \\
\hline & & & $(1.75)$ & & $(2.63)$ & & $(1.78)$ \\
\hline Mother alive and & good health & & -0.038 & & 0.043 & & -0.073 \\
\hline & & & $(0.62)$ & & $(0.93)$ & & $(1.33)$ \\
\hline Chronic disease & & $\begin{array}{c}-2.803^{* * *} \\
(3.40)\end{array}$ & & & & & \\
\hline Self-rated health & tus (ordered) & & & $0.963^{*}$ & & & \\
\hline & & & & $(1.71)$ & & & \\
\hline Self rated health: & or, very poor or fair & & & & & $-0.589^{* * *}$ & \\
\hline & & & & & & (3.27) & \\
\hline Variance $\sigma_{R}^{2}$ & & $\sigma_{R}^{2}=3.35$ & $; t=31.35$ & $\sigma_{R}^{2}=3.28$ & $; t=32.82$ & $\sigma_{R}^{2}=3.26$ & $; t=42.09$ \\
\hline Correlation & & $\rho=0.37$ & $; \mathrm{t}=2.77$ & $\rho=-0$. & $\mathrm{t}=1.04$ & $\rho=-0$. & $7 \mathrm{t}=1.27$ \\
\hline Log likelihood & & & 4.14 & & .17 & & 9.83 \\
\hline
\end{tabular}

Source: Survey PRI 2003.

Notes: Estimates from simultaneous recursive models, with robust standard errors. The sample includes 2570 observations. Absolute values of $t$ statistics are in parentheses, significance levels being respectively $1 \%\left({ }^{* * *}\right), 5 \%\left(\left(^{* *}\right)\right.$ and $10 \%\left(\left(^{*}\right)\right.$. The ordered Probit equation includes a set of threshold values. The different regressions also include a set of country of origin dummies. 